\title{
LA CREACIÓN POR EL TRIBUNAL SUPREMO \\ DE LA PRESTACIÓN POR MATERNIDAD SUBROGADA: A PROPÓSITO DE LAS SSTS DE 25 DE OCTUBRE DE 2016 Y DE 16 DE NOVIEMBRE DE 2016
}

\author{
THE CREATION BY THE SUPREM COURT OF THE BENEFIT \\ FOR SURROGATE MOTHERHOOD: FOR THE PURPOSE \\ OF THE JUDGMENTS OF THE SUPREME OF 25TH OCTOBER \\ AND OF 16TH NOVEMBER 2016
}

\author{
Jesús R. Mercader Uguina \\ Catedrático de Derecho del Trabajo y de la Seguridad Social \\ Universidad Carlos III de Madrid
}

Recibido: 25.01.2017 / Aceptado: 30.01.2017

DOI: https://doi.org/10.20318/cdt.2017.3633

\begin{abstract}
Resumen: El objeto del presente trabajo es el análisis de dos sentencias del Tribunal Supremo, una de 26 de octubre de 2016 y otra de 18 de noviembre de 2016, en las que se estudia el reconocimiento de la prestación por maternidad a progenitores que acudieron para serlo a la gestación por sustitución. En ambas resoluciones, el TS estima la prestación por maternidad a pesar de lo dispuesto en las instancias inferiores. No obstante, la cuestión no es pacífica, acompañándose dichas sentencias de votos particulares que hacen plantearse el estado de la cuestión en el ordenamiento español.
\end{abstract}

Palabras clave: maternidad subrogada, interés del menor, prestación por maternidad.

Abstract: The purpose of this paper is the analysis of two judgments of the Supreme Court, one of October 26, 2016 and another of November 18, 2016, which examine the recognition of the maternity benefit to parents who came to be parents Gestation by substitution. In both resolutions, the Supreme Court estimates the maternity benefit despite the provisions in the lower instances. However, the issue is not peaceful, those judgments are accompanied by particular votes that raise the state of the question in the Spanish law.

Keywords: surrogate motherhood, interest of the child, maternity benefit.

Sumario: I. Concepto y concepciones de la maternidad subrogada. II. Las circunstancias de la STS de 25 de octubre de 2016 y de la STS de 16 de noviembre de 2016. III. El diálogo en divergencia de los discursos de las sentencias y las argumentaciones de los votos particulares. 1. El discurso del interés del menor y su uso como canon hermenéutico reforzado. 2. Listado de situaciones protegidas parcialmente abierto. 3. Protección a un estado de necesidad real. 4. Interpretación constitucional. 5. Paternidad biológica con maternidad subrogada. 6. Discriminación por razón de filiación. IV. Riesgos de la "sobreinterpretación" judicial y necesidad de sosiego en espera de la intervención legislativa. 


\section{Concepto y concepciones de la maternidad subrogada}

1. La idea tradicional de familia y, por extensión, la propia de la filiación, se vienen enfrentado en las últimas décadas a los permanentes avances que se han sucedido en medicina y biotecnología. Estos trascendentales cambios han transformado nuestra concepción sobre ideas tradicionales como la maternidad, la paternidad y la filiación, lo que ha venido unido a transformaciones de enorme intensidad en los modelos tradicionales de familia. Se habla ya de una "familia posfamiliar" en la que, junto a sus formas tradicionales, se unen otras radicalmente nuevas ${ }^{1}$.

En este contexto, constituye la maternidad subrogada una de las cuestiones que mayor polémica ha generado en los últimos tiempos. La maternidad subrogada puede materializarse a través de una pluralidad de posibles técnicas que ofrecen reflexiones y respuestas jurídicas no coincidentes: por un lado, la maternidad subrogada tradicional, plena o total (traditional surrogacy), en la que la madre subrogada es también la madre genética, al ser ella la que aporta su material genético para llevar a cabo la gestación; por otro, la maternidad subrogada gestacional o parcial (gestational surrogacy), en la que la madre subrogada no aporta material genético, de modo que la concepción tiene lugar a partir del óvulo u óvulos de una mujer diferente de la madre subrogada, que normalmente es la madre comitente. Partiendo de estas dos modalidades, se pueden distinguir, a su vez, varios supuestos: la pareja comitente aporta el material genético, -tanto óvulo como esperma- y la madre subrogada recibe en su útero el embrión con el fin de gestarlo; la mujer comitente aporta el óvulo fecundado por donante anónimo de esperma; la madre gestante aporta el óvulo que es fecundado con esperma de la pareja de ésta, del padre comitente o por donación de un tercero y; en fin, el material genético no es de ninguno de los comitentes, es aportado por personas ajenas, limitándose la madre subrogada a ceder su útero para gestar el embrión².

2. Pero, definido su concepto, es la existencia de plurales concepciones éticas y jurídicas lo que hace de la maternidad subrogada una cuestión poliédrica dotada de agudas aristas ${ }^{3}$. Como resume el Tribunal Supremo, en asunto tan sensible "por estar en juego derechos de la personalidad que pivotan alrededor de menores no maduros, la complejidad resulta inevitable". Solo es necesario que nos acerquemos al Parlamento para observar con nitidez las formas de entender y enfrentar los numerosos interrogantes que se abren en esta materia.

Si leemos la Proposición no de Ley presentada por el Grupo Parlamentario Mixto, relativa a los contratos de maternidad subrogada, su rechazo es categórico ${ }^{4}$ :

«Los vientres de alquiler suponen una nueva forma de esclavitud de las mujeres (...) Una forma de explotación y tráfico de personas que convierte a los niños en productos comerciales, un producto que se encarga, se compra, se vende e incluso se devuelve y se cambia si no satisface al cliente», palabras empleadas por don Mariano Calabuig, Presidente del Foro de la Familia de España, para describir el nuevo fenómeno de la maternidad subrogada.

El «contrato» de maternidad subrogada es aquél por el que una mujer «alquila»su útero, cosificando uno de sus órganos y, por ende, a la mujer en sí misma.

A este respecto, el Código civil, en materia de contratos, en su artículo 1271, habla de res extra comercio, para hacer referencia a aquello que está fuera del comercio jurídico, fuera del ámbito patrimonial privado y, por tanto, fuera del alcance de la facultad de disposición, quedando excluido de ser objeto

${ }^{1}$ U. BeCK y E. BeCK-Genshein, La individualización. El individualismo institucionalizado y sus consecuencias sociales y politicas, Paidós, Barcelona, 2003, p. 186.

2 Como resume A. J. Vela SÁnchez, Gestación por sustitución o maternidad subrogada: el deseo a recurrir a las madres de alquiler, Diario La Ley, 2011, $\mathrm{n}^{\circ}$ 7608, pp. 1 y 2. Del mismo autor, La maternidad subrogada: Estudio ante un reto normativo, Granada, 2012.

3 Para la diferenciación entre “concepto" y “concepción”, vid. R. DWORKIN, El imperio de la justicia, Barcelona, Gedisa, 1988, p. 60-61.

4 Por la que Grupo Parlamentario Mixto, a instancia de don Carlos Salvador Armendáriz, Diputado de Unión del Pueblo Navarro/UPN, presentan la siguiente Proposición no de Ley relativa a los contratos de maternidad subrogada (BOCD, 15 de septiembre de 2016). 
de contratación. Tradicionalmente la doctrina ha entendido que el cuerpo y sus elementos, al no ser cosas, sino que pertenecen a la unicidad del sujeto mismo, están fuera del patrimonio, son res extra comercio.

El cuerpo y sus elementos no son bienes apropiables, lo cual implica que no se puede disponer de ellos, ni contratar sobre ellos, ni se pueden adquirir por usucapión, ni tampoco pueden ser embargados, incluyéndose en los bienes conocidos tradicionalmente bajo la fórmula de bienes «inalienables, imprescriptibles e inembargables».

Está claro que los parámetros sobre los que se delinea el debate ofrecen plurales perspectivas éticas. Se ha afirmado que esa contratación es moralmente problemática porque "las mujeres no están programadas para tener hijos y darlos" y "un contrato previo no puede alterar esos impulsos biológicos". Por esa razón se arguye que "se trata de contratos necesariamente desventajosos para una de las partes (la mujer) en la medida en que nunca puede disponer de la adecuada información ex ante sobre lo que pasará en el futuro. En fin, se dice también que "se origina un daño a los hijos de la madre de alquiler, que pudieran pensar, dado que su madre alquila su útero, que ellos van a ser vendidos también cuando su madre necesite dinero". Incluso hay autores que niegan incluso la maternidad por sustitución altruista pues se afirma que es un modelo diseñado para satisfacer "los deseos de los poderosos". Argumentos a los que se une el nacimiento de un verdadero mercado de la maternidad subrogada con fenómenos tan singulares como el denominado "turismo procreativo internacional" o "cross-border reproductive care"6.

Pero lo cierto es que existen también poderosos argumentos para afirmar que la maternidad por sustitución no entraña necesariamente una degradación para la mujer que accede a gestar ni convierte a los niños en mercancías? Si nos acercamos a la Proposición no de Ley presentada por el Grupo Parlamentario de Ciudadanos en esta materia, los argumentos a favor resultan contundentes:

«Hoy la gestación por subrogación constituye una realidad tanto en España como en los países de nuestro entorno, y se ve con la misma naturalidad que otras expresiones de los cambios de percepciones sociales ante instituciones ligadas a nuevos modelos familiares que tienen como denominador común el fijar el marco jurídico en el cual las personas quieren expresar su propia concepción de las relaciones familiares y asumir la condición de progenitores. Piénsese en normas específicas al respecto como la del matrimonio entre personas del mismo sexo (Ley 13/2005, de 1 de julio, por la que se modifica el Código Civil en materia de derecho a contraer matrimonio) o la de adopción internacional (Ley 54/2007, de 28 de diciembre, de Adopción internacional).

Son normas que regulan y garantizan derechos, no desnaturalizan las instituciones y son fruto de la interpretación evolutiva de la Constitución y su acomodo a la realidad de la vida moderna como medio para asegurar su propia relevancia y legitimidad, en conceptos empleados en la Sentencia del Tribunal Constitucional, de 6 de noviembre de 2012, que avala el matrimonio entre personas del mismo sexo, o matrimonio igualitario. En esta sentencia también se destaca que la nueva configuración de esa institución familiar no la convierte en irreconocible en la sociedad española actual, algo completamente aplicable a la gestación por subrogación.

Hace tiempo ya, que la sociedad está demandando una Ley cuyo objetivo sea el de regular la gestación subrogada y garantizar los derechos de todas las personas que intervienen en el proceso, y de forma muy especial, de los menores fruto de esta técnica de reproducción asistida con la finalidad también de extender la posibilidad de acceder a la gestación subrogada -acceso ahora reservado a los más pudientes- $\mathrm{y}$ facilitar con ello la debida tutela de los diferentes derechos.

Entendemos los derechos reproductivos los que buscan proteger la libertad y la autonomía de las personas para darles capacidad reproductiva, sin discriminación por género, edad o raza. Acceder a la paternidad y/o maternidad ha evolucionado con grandes cambios en la reproducción pero el modelo de familia también y ambos cambios deben ir juntos, es un derecho a la igualdad que se debe garantizar siempre» ${ }^{8}$.

${ }^{5}$ Los entrecomillados pertenecen a los argumentos de diversos autores citados por P. DE LORA, Entre el vivir y el morir, Mexico, Fontamara, 2003, pp. 163-164.

${ }^{6}$ A. Calvo Caravaca, J. Carrascosa González, Derecho Internacional Privado, Granada, Comares, 2016, II, p. 389.

7 P. DE LORA, Entre el vivir y el morir, cit., pp. 164-165.

8 Proposición no de Ley 51/2016, presentada por el Grupo Parlamentario de Ciudadanos, con el siguiente objeto: la Asamblea de Madrid insta al Gobierno de la Comunidad de Madrid a instar al Gobierno de la Nación a impulsar, de forma inmediata, 
3. Pero si el debate social con el trasfondo político subyacente es intenso, el jurídico no le va a la zaga. El Tribunal Supremo, Sala de lo Civil, en la sentencia de 6 de febrero de $2014\left(\mathrm{R}^{\mathrm{o}}\right.$ 245/12) y en el auto de 2 de febrero de 2015, ha dejado clara su postura sobre la ilegalidad de estas prácticas. El Tribunal Supremo entiende que la aceptación en el orden jurídico español de la filiación contenida en la certificación registral extranjera daña el orden público internacional español.

Para ello utiliza el Tribunal Supremo varios argumentos que pueden resumirse en los siguientes tres "discursos", siguiendo a Calvo/Carrascosa quiénes, por otra parte, realizan una aguda y bien fundada crítica de los mismos": $1^{\circ}$ ) El discurso de la dignidad: "En nuestro ordenamiento jurídico y en el de la mayoría de los países con ordenamientos basados en similares principios y valores, no se acepta que la generalización de la adopción, incluso internacional, y los avances en las técnicas de reproducción humana asistida vulneren la dignidad de la mujer gestante y del niño, mercantilizando la gestación y la filiación, «cosificando» a la mujer gestante y al niño". $2^{\circ}$ ) El discurso de la discriminación económica. Indica el Tribunal Supremo que la gestación por sustitución, constituye una técnica que permite a "determinados intermediarios realizar negocio con ellos, posibilitando la explotación del estado de necesidad en que se encuentran mujeres jóvenes en situación de pobreza y creando una especie de «ciudadanía censitaria» en la que solo quienes disponen de elevados recursos económicos pueden establecer relaciones paterno filiales vedadas a la mayoría de la población". $3^{\circ}$ ) El discurso del fraude: "En el caso objeto de este recurso, los vínculos eran intensos puesto que de lo actuado se desprende que los recurrentes, nacionales y residentes en España, se desplazaron a California únicamente para concertar el contrato de gestación por sustitución y la consiguiente gestación, parto y entrega de los niños, porque tal actuación estaba prohibida en España. La vinculación de la situación jurídica debatida con el Estado extranjero cuya decisión se solicita sea reconocida es completamente artificial, fruto de la «huida» de los solicitantes del ordenamiento español que declara radicalmente nulo el contrato de gestación por sustitución, no reconoce la filiación de los padres intencionales o comitentes respecto del niño que nazca como consecuencia de dicha gestación por sustitución (sin perjuicio de la reclamación de paternidad que pueda efectuar el padre biológico), e incluso tipifica ciertos supuestos corno delito, también cuando la entrega del menor se ha producido en el extranjero (art. 221.2 del Código Penal)".

4. Pero lo cierto es que el debate jurídico ha irradiado sus efectos al ámbito de lo social y dos recientes sentencias de la Sala de lo Social, la STS de 25 de octubre de 2016 (Asunto maternidad subrogada realizada en Nueva Delhi) y la STS de 16 de noviembre de 2016 (Asunto maternidad subrogada realizada en California), han venido a poner sobre la mesa el anterior debate pero ahora sobre la base del alcance de la protección social. El primero de los citados pronunciamientos inicia su razonamiento desde la propia consciencia de su enorme complejidad jurídica subrayando que "los propios escritos procesales constituyen buena prueba de ello, al invocar normas de diversa procedencia (Tratados Internacionales de Derechos Fundamentales, Directivas de la UE, Leyes orgánicas y ordinarias, Reglamentos e incluso Decisiones Administrativas -Instrucciones, Circulares, Resoluciones-) y contenido (civilistas, antidiscriminatorias, laborales, asistenciales, registrales), así como sentencias de los distintos Tribunales competentes para su interpretación (TEDH, TJUE, TS, TTSSJJ)". Un debate en todo caso verdaderamente interesante en el que la ponderación de los muy sensibles intereses en juego requiere, como veremos, alcanzar equilibrios inestables ${ }^{10}$.

una Ley de regulación de Gestación Subrogada que garantice los derechos de todas las personas intervinientes en el proceso y, de forma especial, a los menores fruto de esa técnica de reproducción (BOAM, no 49 de 10 de marzo de 2016). Más recientemente, en la misma dirección la Proposición no de Ley (BOCD, 17 de enero de 2017) por la que se solicita que: «El Congreso de los Diputados insta al Gobierno a llevar a cabo las instrucciones precisas a la Seguridad Social a fin de que los progenitores de menores alumbrados por gestación subrogada puedan disfrutar de las prestaciones por maternidad y paternidad en relación a la jurisprudencia emanada de las actuaciones del Tribunal Europeo de Derechos Humanos y del Tribunal Supremo.»

9 A. Calvo Caravaca, J. Carrascosa González Derecho Internacional Privado, cit, pp. 396-398.

10 Han sido numerosos los comentarios que se han realizado por la doctrina laboral sobre esta materia a lo largo de los últimos años, al respecto: F.J. Hierro Hierro, Gestación por sustitución y prestación de maternidad: SJS núm. 2 Oviedo 9 abril 2012 (AS 2012, 942), Aranzadi Social: Revista Doctrinal, 2012, nº 6, pp. 53-59; A. Selma Penalva, Vientres de alquiler y prestación por maternidad, Aranzadi Social: Revista Doctrinal, 2013, nº 9, pp. 223-244; J.A. PANIzo RoBles, La maternidad por contrato de sustitución sigue sin estar amparada por la acción protectora de la Seguridad Social (Sentencia 


\section{Las circunstancias de la STS de 25 de octubre de 2016 y de la STS de 16 de noviembre de 2016}

5. En la STS de 25 de octubre de 2016 ( $\left.\mathrm{R}^{\mathrm{o}} 318 / 2015\right)$, el objeto del conflicto gira en torno al reconocimiento o denegación del derecho a lucrar prestaciones de maternidad pedidas por un varón cuya paternidad de dos menores se acredita como filiación por naturaleza en el Registro civil consular español, junto a la de la madre ${ }^{11}$.

El solicitante de la prestación por maternidad tuvo dos hijas que fueron inscritas en el Registro Civil del Consulado de España en Nueva Delhi. Las dos hijas nacieron en Nueva Delhi mediante la técnica de reproducción humana asistida, en la que el demandante fue el padre genético y los óvulos fueron de una donante que gestó por subrogación a favor del demandante. Poco después del nacimiento e inscripción de las dos hijas en el Registro Civil español, el padre y la madre pactaron que el padre de las hijas ejerciera exclusivamente todas las funciones y obligaciones que se derivan de la patria potestad, incluyendo el cuidado exclusivo y la custodia y todos los derechos como padre, debido a la imposibilidad de la madre para ejercer su función. En la misma fecha, en declaración jurada ante notario de Nueva Delhi, la madre declara, que por razones geográficas e imposibilidad, no quiere ejercer ninguna de las funciones inherentes al ejercicio de guardia y custodia, y, por ello, concede al otro progenitor el ejercicio legal de estas funciones, aceptando que la guardia y custodia sea ejercida solo por el padre de las niñas.

El demandante reclamó al INSS prestación por maternidad por el nacimiento de sus dos hijas y en relación con el descanso por maternidad, con fecha de inicio idéntica a la del nacimiento, que fue denegada por dicha entidad gestora por no encontrarse en ninguno de los supuestos previstos en el entonces vigente artículo 133 bis LGSS/1994. Asimismo, fue desestimada la reclamación administrativa previa presentada contra dicha resolución.

El interesado formuló demanda ante el Juzgado de lo Social, que desestimó la pretensión del actor. Desestimada la demanda en la instancia, la sentencia de la Sala de lo Social del Tribunal Superior de Justicia de Cataluña acoge favorablemente el recurso de suplicación del actor y, estima la demanda reconociendo al actor el derecho a percibir la prestación de maternidad, así como el subsidio especial por cada hijo a partir del segundo durante el periodo de 6 semanas inmediatamente posteriores al parto ${ }^{12}$.

del Tribunal Superior de Justicia del País Vasco de 13 de mayo de 2014), Revista de Información Laboral, 2014, nº 5, pp. 149-154; A.M. SÁncheZ-MoraledA, ¿Tienen permiso las madres «subrogantes» al permiso y a la prestación por maternidad?, Revista Aranzadi Doctrinal, 2014, n 9/10, pp. 141-156; M. D. ORTIZ VIDAL, La gestación por sustitución y las prestaciones sociales por maternidad / paternidad en España y la novísima jurisprudencia del Tribunal de Justicia de la Unión Europea, Nueva Revista Española de Derecho del Trabajo, 2015, nº 180, pp. 241-266; M. J. Moreno Pueyo, Maternidad subrogada y prestación de maternidad, Revista del Ministerio de Empleo y Seguridad Social, 2015, n 116, pp. 21-56; O. REQUENA Montes, El derecho a la prestación de maternidad en los supuestos de maternidad subrogada, Nueva Revista Española de Derecho del Trabajo, 2015, $\mathrm{n}^{\circ}$ 181, pp. 339-346 V. CORDERo Gordillo, La prestación por maternidad en los supuestos de gestación por sustitución, Trabajo y Derecho: nueva revista de actualidad y relaciones laborales, 2015, $\mathrm{n}^{\circ}$ 7/8, pp. 7284; P. Menéndez Sebastián, S. J. De Castro Mejuto, ¿Mater Semper certa est?. La maternidad subrogada como situación generadora de derechos laborales. Pauta de urgencia para la solución de un intrincado litigio, Revista General de Derecho del Trabajo y de la Seguridad Social, 2015, $\mathrm{n}^{\circ}$ 40; C. Molina Navarrete, Libertad de procrear, vida en familia y prestaciones de maternidad subrogada: impacto nacional de la jurisprudencia del Tribunal Europeo de Derechos Humanos (Comentario a la Sentencia del TEDH de 27 de enero de 2015, asunto «Paradiso y Campanelli c. Italia», CEF-RTSS, 2016, nº 399, pp. 195-204; M.F. Trejo Chacón, Prestación de maternidad en los supuestos de gestación por sustitución. STSJ Las Palmas de Gran Canaria de 27 de marzo de 2015 (AS 2015, 1993), Nueva Revista Española de Derecho del Trabajo, 2016, n 185, pp. 319-329; FJ. Hierro Hierro, Maternidad subrogada y prestaciones de la Seguridad Social, Nueva Revista Española de Derecho del Trabajo, 2016, nº 190, pp. 179-222; M. J. Cervilla Garzón, El avance hacia el reconocimiento del derecho a la prestación por maternidad y otros derechos sociales en los supuestos de gestación por sustitución, Nueva Revista Española de Derecho del Trabajo, 2016, n 188, pp. 179-200; A. ARIAs DomínguEZ, Maternidad subrogada y prestaciones de maternidad y paternidad, Revista de Derecho de la Seguridad Social, 2016, nº 8, pp. 75-96; J. Gorelli Hernández, La prestación por maternidad en los casos de gestación por sustitución o maternidad subrogada (vientres de alquiler), Revista Aranzadi Doctrinal num.1/2017.

11 Sobre los referidos pronunciamientos, vid. R. Presa García-LóPez, Gestación por sustitución y prestaciones por maternidad. (Análisis de los nuevos criterios administrativos con ocasión de las SSTS de 25 de octubre y de 16 de noviembre de 2016). Aranzadi digital num.1/2017; C. Molina Navarrete, Prohibida la "nacional", ¿protegemos la "gestación/maternidad subrogada internacional” con prestaciones sociales?, CEF-RTSS, 2017, n 406, pp. pp. 199-210.

12 Sobre el citado pronunciamiento véanse los comentarios de J.M. GÓMEZ MuÑoz, Reconocimiento de la prestación de maternidad a padre biológico de menores nacidos por gestación de sustitución en Estados Unidos. STSJ Cataluña, de 1 de 
Frente a la misma acude el INSS en casación para unificación de doctrina aportando, como sentencia contradictoria con la recurrida, la dictada por la Sala de lo Social del Tribunal Superior de Justicia del País Vasco de 13 de mayo de 2015, que desestima la pretensión de reconocimiento de la prestación de maternidad solicitada por una mujer que había acudido al condado de San Diego (EE.UU) para concertar una gestación por sustitución de la que nacieron dos niños, inscritos en el Registro local. La Corte Superior de California declaró a la demandante única progenitora legal de los niños, atribuyéndole su custodia legal y física. El Tribunal Supremo, por las razones que seguidamente, veremos, procede a conceder las prestaciones.

Es importante apuntar, como lo hace uno de los votos particulares que acompañan al citado pronunciamiento, que resulta más que dudosa la existencia de contradicción, requisito absolutamente imprescindible para que proceda la casación en unificación de doctrina. Y ello en la medida en que: "Hay diferencias fácticas entre los supuestos comparados que resultan relevantes para construir tal doctrina. Así, mientras que en el caso de la sentencia de contraste estamos sin lugar a dudas ante un supuesto de maternidad subrogada o de gestación por sustitución, en que la dicha gestación ha sido llevada a cabo por una mujer que renuncia a la filiación tras el parto; en el caso que aquí se plantea no existe sustitución de la mujer gestante, sino que el varón concierta la gestación con una mujer, con la que, tras el parto y tras la inscripción como madre biológica de los dos hijos nacidos, pactan que el varón asumirá, en exclusiva, "todas las funciones y obligaciones que se derivan de la patria potestad", pudiendo instalarse con las menores donde quisiera.

6. Por su parte, la STS de 16 de noviembre de 2016 ( $\left.\mathrm{R}^{\mathrm{o}} 3146 / 2015\right)$, resuelve sobre otro supuesto, en este caso rotundamente claro de gestación por sustitución. La misma se lleva a cabo conforme a la legalidad vigente en el estado de California (Estados Unidos). En dicho estado, celebrado el contrato de gestación por sustitución entre los padres comitentes y la madre biológica, el tribunal competente dicta (con anterioridad al nacimiento del hijo) una resolución que determina la filiación del menor en favor de los padres comitentes. Como consecuencia de esta resolución judicial no aparecerá referencia alguna a la madre biológica en la inscripción registral de filiación, de manera que, producido el nacimiento del hijo, su filiación es inscrita a favor de los comitentes. Con posterioridad, la madre subrogada alumbra al hijo de dichos padres en un Hospital de San Diego (California). El hijo nacido es inscrito en el Registro Civil de San Diego y poco después en el Consulado General de España en los Ángeles. Figuran como progenitores los padres comitentes de la maternidad subrogada.

La actora solicitó la prestación de maternidad, siendo denegada por el INSS por no ser considerada la gestación de un menor por útero subrogado como situación protegida a los efectos de la prestación de maternidad. No estando conforme la parte actora con la resolución anterior, interpuso reclamación previa y la Dirección Provincial del INSS dictó resolución desestimatoria.

La interesada formuló demanda ante al Juzgado de lo Social, que la desestimó. Contra dicha sentencia, interpuso la interesada recurso de suplicación, y la Sala de lo Social del Tribunal Superior de Justicia de Madrid dictó sentencia desestimatoria. Contra la anterior, sentencia la interesada formuló recurso de casación para la unificación de doctrina ante el Tribunal Supremo, siendo estimado mediante sentencia de 16 de noviembre de 2016, por lo que casa y anula la sentencia recurrida y estima el recurso interpuesto por la interesada y la demanda formulada, declarando el derecho de la actora a percibir la prestación de maternidad durante 112 días.

\section{El diálogo en divergencia de los discursos de las sentencias y las argumentaciones de los votos particulares}

7. Como hemos señalado, los dos pronunciamientos de la Sala de lo Social del Tribunal Supremo se muestran favorables al otorgamiento de la prestación de maternidad. Los argumentos que utiliza 
la Sala para justificar dicha conclusión son plurales: el interés del menor; el carácter parcialmente abierto del listado de situaciones protegidas; la protección a un estado de necesidad real; la interpretación constitucional; o, en fin, la paternidad biológica como maternidad subrogada.

Pero, paralelamente, los citados pronunciamientos, lejos de resultar unánimes, se encuentran acompañados de votos particulares concurrentes y disidentes que cuestionan de manera simétrica los razonamientos que sirven de base al resultado alcanzado por la mayoría de la Sala. La emisión de votos particulares en las sentencias que resuelven el recurso de casación para unificación de doctrina es algo habitual. A lo largo de los últimos años se viene observando un uso acentuado del recurso al voto particular como medio de expresión de la divergente concepción de un determinado problema y como "válvula de escape" que sirve para oxigenar la vida interna del órgano. Sin duda, el recurso al voto particular cuenta en su haber con numerosos puntos positivos que avalan su uso: su capacidad para guiar líneas de jurisprudencia futura o la certeza, claridad y coherencia que proporciona a las resoluciones judiciales, pudiendo servir, en último extremo, al propio desarrollo de la ciencia jurídica ${ }^{13}$.

La intrínseca dificultad de alcanzar la "only right answer" de Dworkin debe animarnos a efectuar un cuidadoso balance argumental de las razones e interés en juego, para, desde el mismo, efectuar una valoración sobre la corrección o incorrección del resultado alcanzado por el Tribunal Supremo. En suma, el diálogo en divergencia de los discursos de las sentencias y las argumentaciones de los votos particulares viene a representar una suerte de juego de espejos que se miran uno en el otro y que al intercambiar su luz dotan de mayor definición a los términos del problema.

\section{El discurso del interés del menor y su uso como canon hermenéutico reforzado}

8. El primer discurso que utilizan los dos pronunciamientos es el relativo al interés del menor. La STS de 25 de octubre de 2016 (el supuesto de Nueva Delhi), razona que si bien "el interés superior del menor no puede erigirse en principio a partir del cual los órganos jurisdiccionales alteren el contenido de las normas y eludan la sujeción al ordenamiento jurídico (art. 9.1 CE) (...) sí constituye un canon interpretativo de relevancia cuando debemos aplicar normas que lo han querido tener presente, como aquí sucede".

El mismo fundamento hermenéutico utiliza la STS de 16 de noviembre de 2016 (el supuesto de California), pero ahora con base en la doctrina de la Sala Primera del Tribunal Supremo en la sentencia de 6 de febrero de 2014 ( $\mathrm{R}^{\mathrm{o}}$ 245/2012), de acuerdo con la cual: "la cláusula general del interés superior del menor, contenida en la legislación, no permite al juez alcanzar cualquier resultado en la aplicación de la misma, sino que su aplicación ha de hacerse para interpretar y aplicar la ley y colmar sus lagunas, pero no para contrariar lo expresamente previsto en la misma". Dicho principio ha de servir para la interpretación de las normas ahora examinadas referentes a la protección de la maternidad.

Sobre esta base, la STS de 25 de octubre de 2016 (el supuesto de Nueva Delhi), utiliza varios argumentos de refuerzo: en primer lugar, que "pese a sus orígenes y denominación, la protección que la Seguridad Social dispensa a la "maternidad" va mucho más allá del descanso asociado al alumbramiento" citando en su apoyo las SSTS 9 de diciembre de 2002 ( $\mathrm{R}^{\mathrm{o}}$ 913/2002); 5 de mayo de 2003 ( $\mathrm{R}^{\mathrm{o}}$ 2497/2002) y STS 15 de septiembre de 2010 ( $\left.\mathrm{R}^{\mathrm{o}} 2289 / 2009\right)$. En segundo término, que la cuestión resulta evidente solo con reparar en que las prestaciones de esta especie se dispensan también en supuestos donde no hay alumbramiento (adopción, acogimiento, etc.). Y en fin que el art. $39 \mathrm{CE}$ proporciona diversos principios que han de presidir nuestra interpretación de las leyes vigentes (art. 53.3 CE): procurar la protección social de la familia, la protección integral de los hijos y velar por los derechos de los niños".

A los anteriores razonamientos añade la STS de 16 de noviembre de 2016 (el supuesto de California) que el "el art. 8 del Convenio Europeo para la protección de los Derechos Humanos y las Libertades Fundamentales, interpretado por el TEDH, en las sentencias de 26 de junio de 2014, Mennesson y Labassee contra Francia, -si bien no se refiere a las prestaciones por maternidad- expresamente toma en consideración, para examinar la cuestión referente a la negativa de Francia a la inscripción en el

13 Una reflexión de fondo sobre los factores en pro -los utilizados resumidamente en el texto- y en contra del instituto del voto particular puede hallarse en F.J. EzQUiaga GanuZAS, El voto particular, Madrid, CEC, 1990, pp. 77-90, especialmente. 
Registro Civil de los menores, el interés superior del menor cuyo respeto ha de guiar cualquier decisión que les afecte".

9. Los anteriores argumentos contrastan con los sostenidos en los votos particulares y, en particular, con el que se incorpora en la STS de 25 de octubre de 2016, reiterado por la STS de 16 de noviembre de 2016. El citado voto rechaza los anteriores argumentos sobre la siguiente base:

Las afirmaciones que sobre el «interés del menor» formula el TEDH lo hace instrumentalmente para condenar la imposibilidad - tanto en la legislación francesa como en la italiana- del reconocimiento de paternidad biológica o del establecimiento de vínculo de filiación por adopción o acogimiento, incluso para el padre biológico que lo haya sido a través de «maternidad subrogada». Porque tanto Francia como Italia no sólo prohíben la «gestación por encargo», sino que, llegando más lejos, impiden también -por considerarlos un fraude- que pueda burlarse la prohibición a través de la adopción o incluso el reconocimiento de paternidad biológica; que es precisamente lo que provoca la censura del TEDH.

En criterio de la Sala $1^{a} \mathrm{TS}$, "cuya doctrina que hemos de seguir en tanto que genuina intérprete en la materia [estado civil de las personas], es precisamente la existencia de tal posibilidad en la legislación española [reconocimiento de filiación biológica; adopción; acogimiento], la que le lleva excluir -a juicio de la Sala $1^{\mathrm{a}}$ - que se utilice como argumento el «interés del menor»; si quieren protegerlo -sostiene la Sala- que los «padres por subrogación» lo hagan a través de los accesibles cauces que la Ley ofrece [reconocimiento de filiación; adopción; y acogimiento]; y no violentando la Ley y el orden público español. Porque -dice- la «aplicación del principio de la consideración primordial del interés superior del menor ha de hacerse para interpretar y aplicar la ley y colmar sus lagunas, pero no para contrariar lo expresamente previsto en la misma. No hacerlo así podría llevar a la desvinculación del juez respecto del sistema de fuentes, que es contraria al principio de sujeción al imperio de la ley que establece el art. 117.1 CE. Hay cambios en el ordenamiento jurídico que, de ser procedentes, debe realizar el parlamento como depositario de la soberanía nacional, con un adecuado debate social y legislativo, sin que el juez pueda ni deba suplirlo»". Y añade, finalmente: "porque lo cierto es -no nos llamemos a engaño- que lo que está en juego en las presentes actuaciones no es tanto el «interés del menor», cuanto el «status» de «padres» a los comitentes en la gestación subrogada tradicional [otra cosa habría de afirmarse sobre la subrogación «gestacional»]".

\section{Listado de situaciones protegidas parcialmente abierto}

10. Se afirma en el texto de la STS de 25 de octubre de 2016 que "la maternidad por subrogación, como su propio nombre indica, puede abordarse como una especie o subtipo reconducible a la categoría general" y que "la relativa apertura del elenco de supuestos protegidos [por el RD 295/2009, de 6 de marzo], permite cierta flexibilidad interpretativa que antes no existía". A lo que se añade que "en todo caso, pugna con la lógica más primaria que se deniegue la prestación en los supuestos de gestación por sustitución cuando se reconocería ex lege si el solicitante se hubiera limitado a adoptar o a acoger a un menor, o a manifestar que lo ha engendrado junto con la madre".

11. El voto particular que acompaña a ese mismo pronunciamiento discrepa de este planteamiento:

En primer lugar, porque parte de una petición de principio que es la identificación en la naturaleza jurídica, porque la misma no depende del nombre que se atribuya a la figura, sino de las consecuencias -efectos jurídicos- que a ellas les otorgue el legislador.

En segundo lugar, en cuanto a la tentación de hacer una interpretación extensiva, "hay que recordar que con carácter general la misma se ha excluido en materia de Seguridad Social, pues el principio de legalidad no permite otra interpretación que la literal, sin perjuicio de situaciones excepcionales", con cita de una larga serie de pronunciamientos. Más en concreto, se afirma que no hay que olvidar que tal posibilidad -analogía/interpretación extensiva- ha sido expresamente rechazada por la Sala justamente en la concreta materia debatida -prestaciones por maternidad-, que rehusaron expresamente no ya la analogía, sino incluso la interpretación extensiva a los supuestos no contemplados -entonces- de acogimiento y adopción múltiple, basándose en que "es imposible aceptar una interpretación 
extensiva ... [pues] no se trata de una omisión involuntaria de la referida regulación... [habida cuenta de $l a]$ necesidad de que también la jurisprudencia se acomode a aquella voluntad legislativa sin extenderla más allá de sus previsiones, en atención al principio de legalidad de obligado respeto - art.125 CE".

En tercer lugar, tampoco existe laguna que llenar, porque se trata de un supuesto ilegal a tenor de lo establecido en el art. 10 de la Ley 14/2006, sobre Técnicas de Reproducción Humana Asistida. De igual modo, tampoco se da identidad de razón comparando la «maternidad subrogada» y los supuestos que el citado art. 37.4 ET regula [acogimiento; adopción], ni se deja de excluir la semejanza el hecho de que las situaciones expresamente protegidas por la ley [adopción y acogimiento] están dotados de una oficialidad -intervención de las autoridades administrativas y judiciales- que comporta toda clase de garantías para los intereses en juego [tanto de la madre biológica como del menor]; esencial característica de oficialidad -con su correlativo marchamo de seguridad jurídica- que está ausente en un contrato privado, y cuya carencia no subsana el hecho de que, a posteriori, un Tribunal extranjero -en su caso- pueda confirmar la eficacia del negocio jurídico que las partes han suscrito sin intervención oficial ni garantía algunas; con independencia, insisto, del desajuste de tal negocio con nuestros principios jurídicos más elementales en orden a la tutela de la personalidad y dignidad humanas.

\section{Protección a un estado de necesidad real}

12. Subraya la STS de 25 de octubre de 2016 , que, cuando la Sala Primera de este Tribunal niega la inscripción registral de los hijos habidos mediante maternidad subrogada, lleva cuidado en atender las necesidades familiares que hayan surgido de facto. A lo anterior añade que "para el TEDH uno de los puntos muy relevantes a considerar es el referido a la vida privada de las menores que están integradas en una unidad familiar, bien que sea como consecuencia de una maternidad subrogada que las leyes nacionales proscriben. Esa dimensión se recalca todavía más cuando uno de los miembros de la unidad familiar es quien engendró al niño". A la luz de ello, "cuando el padre (biológico, tras maternidad subrogada) es el único de los progenitores que materialmente está al cuidado de las menores la única forma de atender la situación de necesidad consiste en permitirle al acceso a las prestaciones. Unas prestaciones, obvio es, que están reconocidas por nuestras Leyes y que se han denegado como consecuencia de que la gestación deriva de un negocio jurídico nulo. Lo que estamos haciendo, en contra de lo que el escrito del recurso entiende, es interpretar las normas sobre prestaciones de maternidad no solo a la luz de la "realidad social del tiempo en que han de ser aplicadas, atendiendo fundamentalmente al espíritu y finalidad de aquella" (art. 3.1 CC) sino, muy especialmente, a la vista del tenor de otros preceptos. No se trata de violentar lo preceptuado por el legislador sino de aquilatar el alcance de sus previsiones, armonizando los diversos mandatos confluyentes".

Por su parte, en la STS de 16 de noviembre de 2016, se aduce que el menor nacido tras la gestación por sustitución forma un núcleo familiar con los padres comitentes, que le prestan atención y cuidados parentales y tienen relaciones familiares "de facto", por lo que debe protegerse este vínculo, siendo un medio idóneo la concesión de la prestación por maternidad.

13. Por su parte, sobre estos argumentos del voto particular considera que el razonamiento fundado en la doctrina sentada por el TEDH al caso resulta cuestionable: en primer lugar, porque el supuesto que resuelve el TEDH no es el caso de España, "pues el comitente -padre biológico- puede reconocer como hijo al fruto del contrato de subrogación; y la comitente -no aportante genética- puede adoptarlo; de manera que el desamparo del menor únicamente se produce porque los comitentes no quieren acudir al expediente que el legislador les pone a su alcance para proteger al niño, sino que lo que pretenden -como es el caso- es que se les reconozca su estatus de padres por el exclusivo hecho de una «gestación por subrogación» que está prohibida en nuestro país". En segundo lugar, el voto discrepa de la afirmación que se hace en la sentencia aprobada, sosteniendo que «cuando el padre (biológico, tras maternidad subrogada) es el único de los progenitores que materialmente está al cuidado de las menores, la única forma de atender la situación de necesidad consiste en permitirle el acceso a las prestaciones». La afirmación sería cierta si se completa el texto añadiendo la precisión de que tal acceso a las presta- 
ciones, habría de hacerse como tal padre biológico -no como comitente en un contrato de «gestación por encargo»- tras reconocerle como hijo biológico suyo; prestaciones accesibles a la otra parte comitente, si media adopción [no hay que olvidar que las posibilidades de adopción alcanzan también a las parejas de hecho homosexuales, ya implícitamente con la Ley 13/2005, de 1 de julio; y más claramente desde la Ley 26/2015, de 28 de julio, que extiende la viabilidad a los supuestos de ruptura]".

\section{Interpretación constitucional}

14. Señala la STS de 25 de octubre de 2016 que "nuestro Derecho preconiza la nulidad del contrato de maternidad por subrogación. Al mismo tiempo, la LGSS contempla la protección de la maternidad y paternidad, sin mayores restricciones. No es que los bloques normativos estén enfrentados, sino que obedecen a lógicas diversas y también distinta es su aproximación el supuesto de hecho". A lo anterior se añade que "al intérprete corresponde la ardua tarea de armonizar del modo más coherente posible esas magnitudes heterogéneas". "Cada norma singular no constituye un elemento aislado e incomunicado en el mundo del Derecho, sino que se integra en un ordenamiento jurídico determinado, en cuyo seno, y conforme a los principios generales que lo informan y sustentan, deben resolverse las antinomias y vacíos normativos, reales o aparentes, que de su articulado resulten" (SSTC 233/1999, de 16 de diciembre; 150/1990, de 4 de octubre; 222/2006, de 6 de julio). De este modo, hemos de conjugar los diversos mandatos normativos procurando el resultado más acorde a las premisas constitucionales". Por otro lado, "el ordenamiento laboral no es ajeno al reconocimiento de efectos en casos de negocios jurídicos afectados de nulidad. Por ejemplo, cuando se reconoce el derecho al salario por el tiempo ya trabajado al amparo de un contrato que resultase nulo (art. 9.2 ET); se establece pensión de viudedad en determinados casos de nulidad matrimonial (art. 220.3 LGSS/2015); se acotan los efectos de la ausencia de permiso de trabajo (art. 36.5 LOEx 4/2005); se conceden ciertos efectos a los matrimonios poligámicos, etc".

En suma, concluye la Sala: "que una Ley Civil prescriba la nulidad del contrato de maternidad por subrogación no elimina la situación de necesidad surgida por el nacimiento del menor y su inserción en determinado núcleo familiar; y tal situación de necesidad debe ser afrontada desde la perspectiva de las prestaciones de Seguridad Social procurando que esos hijos no vean mermados sus derechos. Y aquí nos encontramos con un contrato de maternidad por subrogación que es nulo pero que ha desplegado sus efectos, en particular los que interesan: inserción de las menores nacidas en el núcleo familiar de quien solicita las prestaciones por tal motivo". De este modo, "el art. $39.3 \mathrm{CE}$ obliga a los padres a prestar asistencia a los hijos habidos "dentro o fuera del matrimonio". En el supuesto que abordamos, no cabe duda de que quien solicita las prestaciones es el padre (biológico, pero también registral) de las dos menores nacidas en La India y que resulta más acorde con ello permitirle la atención que las prestaciones económicas persiguen. De igual modo, la "protección integral de los hijos, iguales éstos ante la ley con independencia de su filiación" (art. 39.2 CE), aconseja no adicionar causas de exclusión ignoradas por la LGSS al establecer sus prestaciones".

La conciliación de la vida familiar y laboral, "que es principio implícito en esos mandatos y aparece asumido de manera robusta en múltiples pronunciamientos de la jurisprudencia (constitucional, pero también ordinaria) aparece asimismo como canon imprescindible a la hora de aquilatar el alcance de derechos legalmente conferidos a partir de la existencia de un menor. Cuando la STJUE 18 marzo 2014, C-167/12 aborda la eventual protección de las Directivas 92/85/CEE y 2006/54/CE a los casos de prestaciones por maternidad, advierte que se trata de una institución regulada "evitando que la acumulación de cargas que deriva del ejercicio simultáneo de una actividad profesional perturbe dichas relaciones".

15. El voto particular contesta los anteriores razonamientos subrayando, en primer lugar, que la sentencia parte de dos consideraciones de índole diversa: a) de un lado, la necesidad de armonizar del modo más coherente posible magnitudes "heterogéneas" [la nulidad del contrato de "maternidad subrogada» en la LRHA y la protección de la maternidad/paternidad en la LGSS]; y b) de otro, que el «ordenamiento laboral no es ajeno al reconocimiento de efectos en casos de negocios jurídicos afectados de nulidad». 
En relación con la primera cuestión, el voto particular considera que "resulta por completo ajeno a la armonía del Derecho que una situación que el legislador -y la sociedad- consideran benéfica y digna de protección [maternidad; adopción; acogimiento], sea interpretada de manera forzada para dar cabida en ella a otra situación que para el legislador -e incluso para gran parte de la sociedad- merece reproche jurídico y/ o moral. Con ello, entiendo - con el mayor respeto a la opinión contraria- que no se interpreta armónicamente el Derecho, sino que en la práctica viene a defraudarse. Sin que en apoyo de tal solución sea eficazmente invocable el interés del menor, porque ya se ha visto que el mismo puede ser protegido (...) a través del reconocimiento de paternidad, acogimiento y adopción. Pero -realmente- lo que aqui se pretende por el reclamante, repito, no es proteger aquel interés, sino dar oficial carta de naturaleza y efectos jurídicos plenos a la "gestación por subrogación»". A ello añade el citado voto que: "no creo que constituya armónica interpretación de las leyes el dar protección prestacional a una situación a la que el legislador niega validez jurídica y para la que -en obligada consecuencia- la jurisprudencia rechaza su acceso al Registro Civil por ser contraria al orden público".

Sobre la segunda consideración [efectos de la nulidad], se imponen, a juicio del voto, dos precisiones: (i) que no es lo mismo -ni por ello puede darse el mismo tratamiento jurídico- un acto nulo [género] que un acto contrario a las leyes [especie]: todos los actos contrarios a la ley son nulos, pero no todos los actos nulos son contrarios a las leyes; y (ii) que los efectos de los actos laborales contrarios a las leyes únicamente pretenden paliar los perjuicios causados a una de las partes y/o terceros, y en tanto que el daño no se pueda resarcir sino a través de esos limitados efectos que la ley le atribuye. Así, por ejemplo, el contrato de trabajo nulo no comporta la privación del salario [art. 9 ET], lo cual es de elemental justicia, pero por supuesto que invalida la eficacia de la relación de Seguridad Social, siquiera mantenga la obligación cotizatoria.... Y en concreto, tratándose de "maternidad subrogada», la nulidad del contrato no impide ni afecta-al menos en España-al posible reconocimiento de la filiación biológica, al acogimiento o a la adopción; y por tales medios puede obtenerse perfectamente la protección del menor, si es que es eso lo que se pretende [que no parece ser este el caso].

\section{Paternidad biológica con maternidad subrogada}

16. Atendiendo al supuesto de la STS de 25 de octubre de 2016, la Sala añade un nuevo argumento: "cuando quien reclama las prestaciones es el padre biológico de las neonatas aumentan las razones para acceder a ello. Porque, al margen de la nulidad del negocio sobre gestación (el "alquiler" del "vientre") lo cierto es que estamos ante una realidad contemplada por la LGSS. Carece de sentido admitir la protección cuando nace un hijo fuera del matrimonio, o como consecuencia de una relación sexual esporádica, pero rechazarla en supuestos como el presente". De este modo, el hecho de que el "art. 3.2 del RD 295/2009 contempla el fallecimiento de la madre biológica y, ante su ausencia y la supervivencia del menor, opta por transferir al padre (siendo compatible con el subsidio por paternidad) la prestación económica por maternidad" y que la misma "solución se aplica al caso en que la madre sea trabajadora por cuenta propia y no tuviese derecho a prestaciones, por no hallarse incluida en el Régimen Especial de la Seguridad Social de Trabajadores por cuenta propia o Autónomos ni en una mutualidad de previsión social alternativa". La sala concluye que "la transferencia del derecho a prestaciones por maternidad en estos casos muestra a las claras la finalidad que se asigna a las mismas y concuerda con la interpretación analógica que se viene defendiendo, al no haber mediado conducta fraudulenta para obtener indebidamente prestaciones".

De igual modo, subraya la Sala que "lo cierto es que no apreciamos conducta fraudulenta alguna, abuso de derecho u obtención ilícita de prestaciones que pudiera alterar el resultado a que hemos accedido. Es evidente que pueden plantearse supuestos en que así ocurra y existe, como soporte fáctico de fondo, una gestación por subrogación: casos en que se pretenda una duplicidad de prestaciones; asuntos en los que exista un conflicto entre progenitores biológicos y subrogados; a través de los resortes de nuestro ordenamiento deberán resolverse con arreglo a Derecho. Pero nada de eso ha sido probado, ni siquiera alegado, en el presente supuesto".

Para finalmente recalcar que "estamos ante un supuesto particularmente cualificado en tanto la situación fáctica creada con la cesión o renuncia de derechos por la madre y el abandono de sus obli- 
gaciones como tal sitúa al demandante en posición de progenitor único. Desde la perspectiva de facto no cabe duda de que las menores conviven con quien es y aparece como su progenitor mientras que la madre biológica (y única que aparece con tal título registral) permanece deliberadamente ajena a ese núcleo. Por tanto, la situación de necesidad que las prestaciones de maternidad desean afrontar es evidente que concurre: las menores nacidas por gestación con sustitución forman un núcleo familiar con su padre, que desea prestar los cuidados parentales apropiados, como cualquier otro progenitor".

17. El voto particular se opone al citado modo de razonar. Muestra el mismo, en primer lugar, su disconformidad con el argumento que la sentencia hace respecto de que "cuando quien reclama las prestaciones es el padre biológico de las neonatas aumentan las razones para acceder a ellos". A dicho argumento se opone que, "si las prestaciones se reclaman -como es el caso- invocando el título de la «gestación subrogada», más bien debe afirmarse lo contrario, pues tratándose del padre biológico se pone claramente de manifiesto que los términos de su reclamación se formulan con el claro ánimo de defraudar la ley, pues teniendo en su mano el título habilitante para las prestaciones [su cualidad de padre biológico y reconocimiento de la filiación], opta por intentar basarse en un título prohibido por el legislador, la «gestación subrogada», para así burlar de facto la proscripción legal".

Añade el voto que "de todas formas no debe perderse de vista que el principio de la realidad biológica tiene apoyo constitucional [art. 39.2 CE ] e inspira la regulación civil de la filiación (...), de manera que no parece razonable prescindir -en la decisión del caso debatido- del incuestionado hecho de que el Sr. Juan Enrique es el padre biológico de las niñas nacidas de la gestación pactada, hasta el punto de que si bien su reclamación pivota formalmente sobre la pretendida eficacia de la «maternidad por subrogación», ello no debe ser obstáculo para su reclamación cuando la misma puede corresponderle por otro título -paternidad biológica- ya afirmado en el expediente administrativo e incuestionado por el INSS".

Todo ello lleva a considerar que "lo que en el caso examinado supone, a mi entender, que si bien el derecho reclamado por el Sr. Juan Enrique -prestaciones de maternidad- ha de rechazársele por el expreso título que invoca [«gestación subrogada»] y que ha sido el objeto de debate, argumentación y decisión en el Juzgado de lo Social, en el Tribunal Superior de Justicia y en la propia Sala, de todas formas bien pudiera reconocérsele exclusivamente en base al dato indubitado de ser padre biológico, como sostiene en ya en su inicial solicitud, en la reclamación previa [«...siendo quien suscribe el padre genético y los óvulos ... de una gestante por subrogación»]; dato éste -paternidad biológica- que invoca la sentencia mayoritariamente aprobada como simple elemento coadyuvante en la estimativa de la pretensión, pero que a mi entender es el único soporte de ella".

\section{Discriminación por razón de filiación}

18. A los anteriores argumentos, la sentencia de 16 de noviembre de 2016 añade que la jurisprudencia del Tribunal Europeo de Derechos Humanos [Sentencias «Mennesson», «Labassee» y «Paradiso y Campanelli»] pasa a un primer plano en la «interpretación integradora» de la normativa aplicable [ arts. 45.1 y 48.4 ET ; arts. 133 bis y 133 ter LGSS/1994 ;y art. 2 RD 295/2009 ], hasta el punto de que de "no otorgarse la protección por maternidad -atendiendo a la doble finalidad que tiene... - al menor nacido tras un contrato de gestación por subrogación, se produciría una discriminación en el trato dispensado a éste, por razón de su filiación, contraviniendo lo establecido en los artículos 14 y $39.2 \mathrm{CE}$, disponiendo este último precepto que los poderes públicos aseguran, asimismo, la protección integral de los hijos, iguales estos ante la ley, con independencia de su filiación”.

19. También el voto particular discrepa de tal aserto, "en primer lugar porque ha de tenerse en cuenta que las afirmaciones que sobre el prevalente «interés del menor» formula el TEDH lo hace instrumentalmente para condenar la imposibilidad -tanto en la legislación francesa como en la italianadel reconocimiento de paternidad biológica o del establecimiento de vínculo de filiación por adopción o acogimiento, incluso para el padre biológico que lo haya sido a través de «maternidad subrogada». Porque tanto Francia como Italia no sólo prohíben la «gestación por encargo», sino que llegando más lejos impiden también - por considerarlos un fraude- que pueda burlarse la prohibición a través de la 
adopción o incluso el reconocimiento de paternidad biológica; que es precisamente lo que provoca la censura del TEDH".

\section{Riesgos de la "sobreinterpretación" judicial y necesidad de sosiego en espera de la intervención legislativa}

20. De la lectura de los argumentos tanto de la sentencia mayoritaria como de los votos particulares se extrae la enorme dificultad de alcanzar un resultado que consiga una solución adecuada para dar una respuesta perfecta a la compleja red de intereses en juego. La tutela de la dignidad de la persona a la hora de construir espacios propios de relación social, el hecho de que los menores no deban pagar el precio de los actos de los adultos y la prevalencia de sus intereses en caso de conflicto de intereses o la consideración kantiana del individuo como fin en sí mismo son ideas poderosas que deben ponerse en un lado de la balanza. Pero el otro lado también tiene su peso: la concreta forma de definir las reglas en un Estado de Derecho, el carácter de consenso social que reflejan las leyes, el hecho de que el desarrollo del Estado social deba medir las consecuencias económicas de sus actos y, en fin, que es, precisamente, función del legislador el diseño y definición de sus nuevos espacios de desarrollo.

Y la gran cuestión en estos casos se antoja evidente: ¿Puede el juez avanzar la decisión del legislador o debe esperar a la misma? o, por decirlo de otro modo, ¿ante un vacío de regulación, puede crear el juez una nueva regla jurídica? Es un debate permanente el relativo al papel del "juez legislador", expresión que solo puede ser aceptada en el sentido de que el juez contribuye al proceso de creación jurídica. En términos rigurosos, sin embargo, "no parece que la creatividad judicial pueda ser equiparada a la legislativa, y ello no solo en virtud de los principios de supremacía y reserva de ley, sino sobre todo por la especial posición que ocupan los jueces y por las características que definen el proceso jurisdiccional" ${ }^{14}$.Como resume Atienza, "los jueces pueden ir más allá del Derecho, en cuanto contribuyen a desarrollarlo aunque, naturalmente, no de cualquier manera, sino según criterios de coherencia; pero no pueden ir contra el Derecho, no pueden sustituir el gobierno de las normas por el gobierno de los hombres. Ni que decir tiene que este ejercicio de equilibrio no siempre es fácil de lograr"15.

Si el juez hace de legislador, se produce una deformación integral del ordenamiento jurídico. Omitido el debate del Parlamento y creada una nueva norma, en este caso una prestación de la Seguridad Social, surge la inevitable necesidad de dotarla de contenido. Muestra de ello es, en el caso que nos ocupa, la consulta $\mathrm{n}^{0}$ 29/2016, de 29 de diciembre 16, en la que el INSS establece los oportunos criterios interpretativos que permitan a sus centros gestores la aplicación uniforme de la doctrina sentada por el Tribunal Supremo favorable a la concesión de las prestaciones por maternidad en los supuestos de gestación por sustitución. Un pseudoreglamento sin Ley previa. No debemos olvidar que con el imperio de la ley están también en juego el principio democrático y la propia noción de Estado de Derecho. Es cierto, como señala Laporta, que el riesgo de las "sobreinterpretaciones" judiciales es evidente pues las mismas enfatizan el protagonismo exclusivo del juez en la atribución de significados. Probablemente, limitando estas actuaciones puede pensarse que "la Ley establezca su imperio"17.

Por ello el "Epítome" con el que concluye el voto particular que formula el Magistrado Excmo. Sr. D. José Manuel López García de la Serrana, y al que se adhieren los Magistrados Excma. Sra. Doña María Milagros Calvo Ibarlucea y Excmo. Sr. D. Jesús Souto Prieto, representan de forma clara el sentir de mis anteriores reflexiones: "Con este voto particular no se cuestiona la filiación del menor, ni el derecho del mismo a integrarse en una familia. La discrepancia surge por entender que para causar las prestaciones de la Seguridad Social, como norma general, hace falta reunir los requisitos que para cada una de ellas establece la Ley, sin que quepa hacer caso omiso de ellos cuando concurren otros principios

14 L. Prieto SAnchís, Ideología e interpretación jurídica, Madrid, Tecnos, 1987, p. 111.

15 M. Atienza, La autoridad y los límites del derecho, El Notario del Siglo XXI, 2011, nº 37 (edición on line).

16 Sobre su contenido, vid. R. Presa García-López, Gestación por sustitución y prestaciones por maternidad. (Análisis de los nuevos criterios administrativos con ocasión de las SSTS de 25 de octubre y de 16 de noviembre de 2016). Aranzadi digital $\mathrm{n}^{\mathrm{o}} 1 / 2017$.

17 F. J. LAPORTA, El imperio de la ley, Una visión actual, Madrid, Trotta, 2007, p. 174. 
que ya valoró el legislador sin darles mayor valor, cual permite el art. 53.3 de la Constitución en relación con el 39 de la misma. Por ello, la prestación de maternidad no se puede reconocer a quien no ha sido padre con arreglo a la ley española, so pretexto de proteger al menor, argumento recurrente que serviría para reconocer todo tipo de prestaciones que responden a la necesidad de proteger diferentes situaciones de necesidad: como la orfandad, la viudedad, la incapacidad, la jubilación etc. Con ello se quiere decir que proteger una situación de necesidad no justifica, sin más, el reconocimiento de una prestación". 